\title{
Common Fixed Point Theorems for Generalized Cyclic Contraction Pair in Partial B-Metric Spaces
}

\author{
A. Jennie Sebasty Pritha, U.Karuppiah
}

\begin{abstract}
In this paper, we introduce the notion of generalized cyclic contraction pair with transitive mapping in partial b-metric spaces. Also, we establish some fixed point theorems for this contraction pair. Our results generalize and improve the result of Oratai Yamaod, Wutiphol Sintunavarat and Yeol Je Cho (Fixed Point Theory App. 2015:164) in partial-b-metric spaces.
\end{abstract}

Index Terms: altering distance function, common fixed point, b-metric spaces, partial b-metric spaces, cyclic generalized contraction, transitive mapping.

\section{INTRODUCTION}

One of the recently popular topics in fixed point theory is to show the existence of fixed points of cyclic contraction mappings in several spaces. In 2013, Shukla [1] introduced the concept of partial b-metric spaces. There are number of generalizations of metric spaces and Banach contraction principle. In the sequel, Bakhtin [2] and Czerwik [3] introduced b-metric spaces as a generalization of metric spaces. On the other hand, Mathews [4] introduced the notion of partial metric spaces. Here, he replaced usual metric as partial metric space with the property that the self distance need not to be zero. In this paper, we generalize some fixed point results for cyclic contraction pair in partial b-metric space by using the condition of transitive mapping.
Revised Manuscript Received on July 08, 2019.

A. Jennie Sebasty Pritha*, Department of Mathematics,Holy Cross College (Autonomous), Trichy-620 002. email: jennipretha @ gmail.com.

Dr.U.Karuppiah, Department of Mathematics, St. Joseph's College(Autonomous), Trichy-620 002. email: u.karuppiah@gmail.com

\section{PRELIMINARIES}

Definition 2.1. [5]

Let $\mathrm{A}$ and $\mathrm{B}$ be non-empty subsets of a metric space (X, d). A mapping $f: A \cup B \rightarrow A \cup B$ is called a cyclic contraction if there exists $k \in[0,1)$ such that $d(f x, f y) \leq k d(x, y)$ for all $x \in A$ and $y \in B$

Definition 2.2. [1]

A partial b-metric on a non-empty set $\mathrm{X}$ is a function $P_{b}: X \times X \rightarrow i^{+}$such that for all $x, y, z \in X:$

(i) $x=y$ if and only if $P_{b}(x, x)=P_{b}(x, y)=P_{b}(y, y)$;

(ii) $P_{b}(x, x) \leq P_{b}(x, y)$;

(iii) $\boldsymbol{P}_{b}(x, y) \leq \boldsymbol{P}_{b}(y, x)$;

(iv) there exists a real number $\mathrm{s} \geq 1$ such that

$$
P_{b}(x, y) \leq s\left[P_{b}(x, z)+P_{b}(z, y)\right]-P_{b}(z, z) .
$$

A partial b-metric space is a pair $\left(X, P_{b}\right)$ such that $X$ is a non-empty set and $\mathrm{Pb}$ is a partial $\mathrm{b}$-metric on $\mathrm{X}$. The number $\mathrm{S}$ is called the coefficient of $\left(X, P_{b}\right)$.

Definition 2.3.[8]

The function $\psi:[0, \infty) \rightarrow[0, \infty)$ is called an altering distance function if the following properties hold:

(i) $\psi$ is continuous and non-decreasing;

(ii) $\psi(t)=\mathrm{O}$ if and only if $\mathrm{t}=0$.

Definition 2.4. [6] and [7]

Let $X$ be a non-empty set. The mapping $\alpha: X \times X \rightarrow[0, \infty)$ is said to be transitive if for all $x, y, z \in X, \alpha(x, y) \geq 1, \alpha(y, z) \geq 1 \Rightarrow \alpha(x, z) \geq 1$.

The authors of the accepted manuscripts will be given a copyright form and the form should accompany your final submission.

\section{MAIN RESULTS}

Let $\left(X, P_{b}\right)$ be a partial b-metric space with coefficient s $\geq 1$ and $f, g: X \rightarrow X$ be two self mappings. For all $x, y \in X$, we have 


\section{Common Fixed Point Theorems For Generalized Cyclic Contraction Pair In Partial B-Metric Spaces}

$M_{s}(x, y)=\max \left\{P_{b}(x, y), P_{b}(x, f x), P_{b}(y, g y), \frac{P_{b}(x, g y)+P_{b}(y, f x)}{2 s}\right\}$

If $\mathrm{s}=1$, we have

$M(x, y)=\max \left\{P_{b}(x, y), P_{b}(x, f x), P_{b}(y, g y), \frac{P_{b}(x, g y)+P_{b}(y, f x)}{2}\right\}$

Definition 3.1

Let $\left(X, P_{b}\right)$ be a partial b-metric space. Let A, B be two non-empty closed subsets of $X$ with $s \geq 1, \alpha: X \times X \rightarrow[0, \infty), \psi, \phi:[0, \infty) \rightarrow[0, \infty)$ and $f, g: X \rightarrow X$ be four mappings. The pair ( $\mathrm{f}, \mathrm{g}$ ) is called an cyclic generalized $\alpha-(\psi, \phi, A, B)_{s, \varepsilon}-$ contraction if

(i) $\psi$ and $\phi$ are an altering distance function.

(ii) $\boldsymbol{A} \cup \boldsymbol{B}$ has a cyclic representation with respect to the pair (f,g) that is, $f(A) \subseteq B, g(B) \subseteq A$ and $X=A \cup B$.

(iii) there exists $0<\delta<1$ such that the following condition holds:

$$
x \in A, y \in B \text { with } \alpha(x, y) \geq 1 \text { or } \alpha(y, x) \geq 1
$$

This implies that

$$
\psi\left(S^{\varepsilon} P_{b}(f x, g y)\right) \leq \delta\left[\psi\left(M_{s}(x, y)\right)\right]
$$

where $\varepsilon>1$ is a real constant.

Theorem 3.1

Let $\left(X, P_{b}\right)$ be a $\mathrm{Pb}$-complete partial b-metric space. Let A, B be the non-empty closed subsets of X. Suppose that $\alpha: X \times X \rightarrow[0, \infty)$, $\psi, \phi:[0, \infty) \rightarrow[0, \infty)$

and

$f, g: X \rightarrow X$ such that the pair (f, g) is $\alpha-(A, B)-$ weakly increasing and the following condition hold:

the pair (f, g) is cyclic generalized $\alpha-(\psi, \phi, A, B)_{s, \in}-$ contraction

$\mathrm{f}$ or $\mathrm{g}$ is continuous,

$\alpha$ is a transitive mapping,

If $\{\mathrm{xn}\}$ is sequence is $\mathrm{X}$ such that $\alpha\left(x_{n}, x_{n+1}\right) \geq 1$ and $x_{n} \rightarrow z$ as $n \rightarrow \infty$ then $\alpha(z, z) \geq 1$.

Then $\mathrm{f}$ and $\mathrm{g}$ have a common fixed point in $A \cap B$.

Proof. It is clear that from (1),

$$
S^{\varepsilon} P_{b}(f x, g y) \leq \delta M_{s}(x, y)
$$

for all $x, y \in X$.

Now it follows immediately from (2) that $z \in X$ is a fixed point of $\mathrm{f}$ if and only if $\mathrm{z}$ is a fixed point of $\mathrm{g}$. Choose $x_{0} \in A$, let $x_{1}=f\left(x_{0}\right)$ and since $f(A) \subseteq B$, we have $x_{1} \in B$.

Let $x_{2}=g x_{1}$ and since $g(B) \subseteq A$, we have $x_{2} \in A$.

Continuing this process, we can construct a sequence $\{\mathrm{xn}\}$ in $\mathrm{X}$ such that $x_{2 n+1}=f x_{2 n} \in B, x_{2 n+2}=g x_{2 n+1} \in A$ for all $n \in ¥ \cup\{0\}$.
Since f and g are $\alpha-(A, B)$ weakly increasing, we have $\alpha\left(f x_{0}, g f x_{0}\right) \geq 1$ and $\alpha\left(g x_{1}, f g x_{1}\right) \geq 1$.

This implies that $\alpha\left(x_{1}, x_{2}\right) \geq 1$ and $\alpha\left(x_{2}, x_{3}\right) \geq 1$.

Continuing this process, we obtain

$$
\alpha\left(x_{n}, x_{n+1}\right) \geq 1 \text { for all } n \in ¥ \cup\{0\} \text {. }
$$

From (1)

$\psi\left(S^{\varepsilon} P_{b}\left(x_{n+1}, x_{n+2}\right)\right)=\psi\left(S^{\varepsilon} P_{b}\left(f x_{n}, g x_{n+1}\right)\right) \leq \delta \psi\left(M_{s}\left(x_{n}, x_{n+1}\right)\right)$

for all $n \in ¥ \cup\{0\}$. If $x_{2 n}=x_{2 n+1}$ for some $\mathrm{n}$ or $x_{2 n+1}=x_{2 n+2}$ for some $\mathrm{n}$, then obviously $\mathrm{f}$ and $\mathrm{g}$ have atleast one common fixed point. Now we complete the proof by three steps:

Step 1: We prove that $\lim _{k \rightarrow \infty} P_{b}\left(x_{k}, x_{k+1}\right)=0$.

For each $k \in ¥ \cup\{0\}$, we define $P_{b_{k}}=P_{b}\left(x_{k}, x_{k+1}\right)$. Now assume that $P_{b_{k_{0}}}=0$, for some $k_{0} \in ¥ \cup\{0\}$. This implies that $x_{k_{0}}=x_{k_{0}+1}$

If $k_{0}=2 n$ for some $n \in ¥$, then $x_{2 n}=x_{2 n+1}$

Next to prove that $x_{2 n+1}=x_{2 n+2}$. Since $\alpha\left(x_{2 n}, x_{2 n+1}\right) \geq 1$, we have

$\psi\left(S^{\varepsilon} P_{b}\left(x_{2 n+1}, x_{2 n+2}\right)\right)=\psi\left(S^{\varepsilon} P_{b}\left(f x_{2 n}, g x_{2 n+1}\right)\right) \leq \delta \psi\left(M_{s}\left(x_{2 n}, x_{2 n+1}\right)\right)$

where

$$
\begin{gathered}
M_{s}\left(x_{2 n}, x_{2 n+1}\right)=\max \left\{P_{b}\left(x_{2 n}, x_{2 n+1}\right), P_{b}\left(x_{2 n}, f x_{2 n}\right), P_{b}\left(x_{2 n+1}, g x_{2 n+1}\right),\right. \\
\left.\frac{P_{b}\left(x_{2 n}, g x_{2 n+1}\right)+P_{b}\left(x_{2 n+1}, f x_{2 n}\right)}{2 s}\right\} \\
\leq \max \left\{P_{b}\left(x_{2 n}, x_{2 n+1}\right), P_{b}\left(x_{2 n+1}, x_{2 n+2}\right)\right\} \\
=P_{b}\left(x_{2 n+1}, x_{2 n+2}\right)
\end{gathered}
$$

From (4), we have

$\psi\left(S^{E} P_{b}\left(x_{2 n+1}, x_{2 n+2}\right)\right) \leq \delta \psi\left(P_{b}\left(x_{2 n+1}, x_{2 n+2}\right)\right) \leq \delta \psi\left(S^{E} P_{b}\left(x_{2 n+1}, x_{2 n+2}\right)\right)$.

$\Rightarrow 1 \leq \delta$ this contradicts the fact that $\delta<1$.

Therefore

$$
\psi\left(S^{\varepsilon} P_{b}\left(x_{2 n+1}, x_{2 n+2}\right)\right)=0 \text {. }
$$

Hence

$x_{2 n+1}=x_{2 n+2}$.

Similarly, if $k_{0}=2 n+1$ for some $n \in ¥ \cup\{0\}$, then $x_{2 n+1}=x_{2 n+2}$ gives $x_{2 n+2}=x_{2 n+3}$.

Consequently, the sequence $\left\{P_{b_{k}}\right\}$ becomes constant for $k \geq k_{0}$, then $\lim _{k \rightarrow \infty} P_{b}\left(x_{k}, x_{k+1}\right)=0$

Suppose $P_{b_{k}}=P_{b}\left(x_{k}, x_{k+1}\right)>0$, for all $k \in ¥ \cup\{0\}$.

Now to prove $P_{b}\left(x_{k+1}, x_{k+2}\right) \leq P_{b}\left(x_{k}, x_{k+1}\right)$ for all $k \in ¥ \cup\{0\}$. 
Suppose $P_{b}\left(x_{k+1}, x_{k+2}\right)>P_{b}\left(x_{k}, x_{k+1}\right)$.

If $\mathrm{k}$ is even, then $\mathrm{k}=2 \mathrm{n}$, for some $n \in ¥ \cup\{0\}$, then we have

$$
P_{b}\left(x_{2 n}, x_{2 n+1}\right)>P_{b}\left(x_{2 n}, x_{2 n+1}\right) . \quad \text { Since } \quad x_{2 n} \in A,
$$

$x_{2 n+1} \in B$ and $\alpha\left(x_{2 n}, x_{2 n+1}\right) \geq 1$. we have

$\psi\left(S^{\varepsilon} P_{b}\left(x_{2 n+1}, x_{2 n+2}\right)\right)=\psi\left(S^{\varepsilon} P_{b}\left(f x_{2 n}, g x_{2 n+1}\right)\right) \leq \delta \psi\left(M_{s}\left(x_{2 n}, x_{2 n+1}\right)\right)$

where

$M_{s}\left(x_{2 n}, x_{2 n+1}\right)=\max \left\{P_{b}\left(x_{2 n}, x_{2 n+1}\right), P_{b}\left(x_{2 n}, f x_{2 n}\right), P_{b}\left(x_{2 n+1}, g x_{2 n+1}\right)\right.$,

$$
\begin{gathered}
\left.\quad \frac{P_{b}\left(x_{2 n}, g x_{2 n+1}\right)+P_{b}\left(x_{2 n+1}, f x_{2 n}\right)}{2 s}\right\} \\
=P_{b}\left(x_{2 n+1}, x_{2 n+2}\right)
\end{gathered}
$$

Then we have

$$
\begin{gathered}
\psi\left(S^{\varepsilon} P_{b}\left(x_{2 n+1}, x_{2 n+2}\right)\right)=\psi\left(S^{\varepsilon} P_{b}\left(x_{2 n+1}, x_{2 n+2}\right)\right) \leq \delta \psi\left(S^{\varepsilon} P_{b}\left(x_{2 n+1}, x_{2 n+2}\right)\right) \\
<\psi\left(S^{\varepsilon} P_{b}\left(x_{2 n+1}, x_{2 n+2}\right)\right)
\end{gathered}
$$

Which is a contradiction. Therefore

$P_{b}\left(x_{2 n+1}, x_{2 n+2}\right) \leq P_{b}\left(x_{2 n}, x_{2 n+1}\right)=M_{s}\left(x_{2 n-1}, x_{2 n}\right)$ for all $n \in ¥ \cup\{0\}$.

If $\mathrm{k}$ is odd, then $\mathrm{k}=2 \mathrm{n}+1$ for some $n \in ¥ \cup\{0\}$.

Therefore, we

$P_{b}\left(x_{2 n+2}, x_{2 n+3}\right)>P_{b}\left(x_{2 n+1}, x_{2 n+2}\right)$

Since $x_{2 n+2} \in A, x_{2 n+1} \in B$ and $\alpha\left(x_{2 n+1}, x_{2 n+2}\right) \geq 1$. we have

$$
\psi\left(S^{\varepsilon} P_{b}\left(x_{2 n+3}, x_{2 n+2}\right)\right)=\psi\left(S^{\varepsilon} P_{b}\left(f x_{2 n}, g x_{2 n+1}\right) \leq \delta \psi\left(M_{s}\left(x_{2 n+2}, x_{2 n+1}\right)\right)\right)
$$

$$
\begin{aligned}
& \text { where } \\
& \begin{array}{l}
M_{s}\left(x_{2 n+2}, x_{2 n+1}\right)=\max \left\{P_{b}\left(x_{2 n+2}, x_{2 n+1}\right), P_{b}\left(x_{2 n+2}, f x_{2 n+2}\right), P_{b}\left(x_{2 n+1}, g x_{2 n+1}\right) .\right. \\
\left.\frac{P_{b}\left(x_{2 n+2}, g x_{2 n+1}\right)+P_{b}\left(x_{2 n+1}, f x_{2 n+2}\right)}{2 s}\right\}
\end{array}
\end{aligned}
$$$$
=P_{b}\left(x_{2 n+2}, x_{2 n+3}\right)
$$

Therefore

$$
\begin{gathered}
\psi\left(S^{\varepsilon} P_{b}\left(x_{2 n+3}, x_{2 n+2}\right)\right) \leq \delta \psi\left(S^{\varepsilon} P_{b}\left(x_{2 n+2}, x_{2 n+3}\right)\right) \\
\leq \delta \psi\left(S^{\varepsilon} P_{b}\left(x_{2 n+2}, x_{2 n+3}\right)\right) \\
<\psi\left(S^{\varepsilon} P_{b}\left(x_{2 n+2}, x_{2 n+3}\right)\right)
\end{gathered}
$$

Which is a contradiction. So we have

$$
P_{b}\left(x_{2 n+2}, x_{2 n+3}\right) \leq P_{b}\left(x_{2 n+1}, x_{2 n+2}\right)=M_{s}\left(x_{2 n}, x_{2 n+1}\right) \text { for }
$$$$
\text { all } n \in ¥ \cup\{0\} \text {. }
$$

Hence $P_{b}\left(x_{k+1}, x_{k+2}\right) \leq P_{b}\left(x_{k}, x_{k+1}\right)$ holds. Then $\left\{P_{b}\left(x_{k}, x_{k+1}\right): k \in ¥ \cup\{10\}\right\}$

is bounded below and non-increasing. Then there exists $r$ $\geq 0$ such that

$$
\lim _{k \rightarrow \infty} P_{b}\left(x_{k}, x_{k+1}\right)=r
$$

This implies

$$
\lim _{k \rightarrow \infty} M_{s}\left(x_{k}, x_{k+1}\right)=r
$$

Letting $n \rightarrow \infty$ in (3), using (5), (6) and the properties of $\psi$, we have $\psi\left(s^{3} r\right) \leq \delta \psi(r) \leq \delta \psi\left(s^{3} r\right)$. Since $\delta<1$, we have $\psi\left(s^{3} r\right)=0 \Rightarrow r=0$.

Thus

$$
\lim _{k \rightarrow \infty} P_{b}\left(x_{k}, x_{k+1}\right)=0
$$

Step 2:

We shall prove that $\{\mathrm{xn}\}$ is a $\mathrm{Pb}$ - Cauchy sequence in $\mathrm{X}$. That is for any $\varepsilon>0$, there exists $k \in ¥$ such that $m, n \geq k$, we get $P_{b}\left(x_{m}, x_{n}\right)<\varepsilon$.

Suppose for the contrary assumption, we assume that there exists $\varepsilon>0$ for which we can find two sub-sequences $\left\{x_{m_{k}}\right\}$ and $\left\{x_{n_{k}}\right\}$ of $\{\mathrm{xn}\}$ such that $n_{k}>m_{k} \geq k$

(a) $m_{k}$ is even and nk is odd,

(b)

$$
P_{b}\left(x_{m_{k}}, x_{n_{k}}\right) \geq \varepsilon
$$

(c) nk is the smallest number such that the condition (b) holds, that is

$$
P_{b}\left(x_{m_{k}}, x_{n_{k}-1}\right)<\varepsilon
$$

From (7), (8), (9) and the triangle inequality, we obtain

$$
\begin{aligned}
\varepsilon & \leq P_{b}\left(x_{m_{k}}, x_{n_{k}}\right) \\
& \leq s\left[P_{b}\left(x_{m_{k}}, x_{n_{k}-1}\right)+P_{b}\left(x_{n_{k}-1}, x_{n_{k}}\right)\right]-P_{b}\left(x_{n_{k}-1}, x_{n_{k}-1}\right) \\
& <s\left[\varepsilon+P_{b}\left(x_{n_{k}-1}, x_{n_{k}}\right)\right]-P_{b}\left(x_{n_{k}-1}, x_{n_{k}-1}\right)
\end{aligned}
$$

Letting $k \rightarrow \infty$ in above inequality and using (7)

$$
\varepsilon \leq \limsup _{k \rightarrow \infty} P_{b}\left(x_{m_{k}}, x_{n_{k}}\right)<s \varepsilon
$$

From the triangle inequality, we have

$$
P_{b}\left(x_{m_{k}}, x_{n_{k}}\right) \leq s\left[P_{b}\left(x_{m_{k}}, x_{n_{k}+1}\right)+P_{b}\left(x_{n_{k}+1}, x_{n_{k}}\right)\right]-P_{b}\left(x_{n_{k}+1}, x_{n_{k}+1}\right)
$$

and

$$
P_{b}\left(x_{m_{k}}, x_{n_{k}+1}\right) \leq s\left[P_{b}\left(x_{m_{k}}, x_{n_{k}}\right)+P_{b}\left(x_{n_{k}}, x_{n_{k+1}}\right)\right]-P_{b}\left(x_{n_{k}}, x_{n_{k}}\right)(12)
$$

Letting $\mathrm{k} \rightarrow \infty$ in (11) and (12), from (7) and (10), we have $\varepsilon \leq s\left(\lim _{k \rightarrow \infty} \sup P_{b}\left(x_{m_{k}}, x_{n_{k}+1}\right)\right)$ and $\limsup _{k \rightarrow \infty} P_{b}\left(x_{m_{k}}, x_{n_{k}+1}\right) \leq s^{2} \varepsilon$,

$$
\frac{\varepsilon}{s} \leq \lim _{k \rightarrow \infty} \sup P_{b}\left(x_{m_{k}}, x_{n_{k}+1}\right) \leq s^{2} \varepsilon
$$

this implies that

Again using the above process, we have

$$
\frac{\varepsilon}{s} \leq \lim _{k \rightarrow \infty} \sup P_{b}\left(x_{n_{k}}, x_{m_{k}+1}\right) \leq s^{2} \varepsilon
$$

Finally, we have 


\section{Common Fixed Point Theorems For Generalized Cyclic Contraction Pair In Partial B-Metric Spaces}

$$
P_{b}\left(x_{m_{k}}, x_{n_{k}+1}\right) \leq s\left[P_{b}\left(x_{m_{k}}, x_{m_{k}+1}\right)+P_{b}\left(x_{m_{k}+1}, x_{n_{k}+1}\right)\right]-P_{b}\left(x_{m_{k}+1}, x_{m_{k}+1}\right)
$$

Taking the limit supremum as $\mathrm{k} \rightarrow \infty$ in above inequality, from (7) and (13), we have

$$
\frac{\varepsilon}{s^{2}} \leq \lim _{k \rightarrow \infty} \sup P_{b}\left(x_{m_{k}+1}, x_{n_{k}+1}\right)
$$

Similarly, we have

$$
\lim _{k \rightarrow \infty} \sup P_{b}\left(x_{m_{k}+1}, x_{n_{k}+1}\right) \leq s^{3} \varepsilon
$$

It follows from (15) and (16) that

$$
\frac{\varepsilon}{S^{2}} \leq \lim _{k \rightarrow \infty} \sup P_{b}\left(x_{m_{k}+1}, x_{n_{k}+1}\right) \leq s^{3} \varepsilon
$$

Since $\alpha$ is transitive, we have $\alpha\left(x_{m_{k}}, x_{n_{k}}\right) \geq 1$.

From (1), we have

$$
\psi\left(S^{\varepsilon} P_{b}\left(x_{m_{k}+1}, x_{n_{k}+1}\right)\right)=\psi\left(S^{\varepsilon} P_{b}\left(f x_{m_{k}}, g x_{n_{k}}\right)\right) \leq \psi\left(M_{s}\left(x_{m_{k}}, x_{n_{k}}\right)\right)
$$

Where

$$
\begin{gathered}
M_{s}\left(x_{m_{k}}, x_{n_{k}}\right)=\max \left\{P_{b}\left(x_{m_{k}}, x_{n_{k}}\right), P_{b}\left(x_{m_{k}}, f x_{m_{k}}\right), P_{b}\left(x_{n_{k}}, g x_{n_{k}}\right), \frac{P_{b}\left(x_{m_{k}}, g x_{n_{k}}\right)+P_{b}\left(x_{n_{k}}, f x_{n_{k}}\right)}{2 s}\right. \\
=\max \left\{P_{b}\left(x_{m_{k}}, x_{n_{k}}\right), P_{b}\left(x_{m_{k}}, x_{m_{k}+1}\right), P_{b}\left(x_{n_{k}}, x_{n_{k}+1}\right),\right. \\
\left.\quad \frac{P_{b}\left(x_{m_{k}}, x_{n_{k}+1}\right)+P_{b}\left(x_{n_{k}}, x_{m_{k}+1}\right)}{2 s}\right\}
\end{gathered}
$$

Letting the limit supremum as $\mathrm{k} \rightarrow \infty$ in the above equation and using (8), (7), (13), (14), (17), we have

$$
\begin{aligned}
& \varepsilon=\max \left\{\varepsilon, \frac{\frac{\varepsilon}{s}+\frac{\varepsilon}{s}}{2 s}\right\} \\
& \leq \lim _{\kappa \rightarrow \infty} \sup M_{s}\left(x_{m_{k}}, x_{n_{k}}\right) \\
& \leq \max \left\{s \varepsilon, \frac{s^{2} \varepsilon+s^{2} \varepsilon}{2}\right\} \\
& =S \varepsilon
\end{aligned}
$$

Letting $\mathrm{k} \rightarrow \infty$ in (18), we obtain

$$
\begin{aligned}
& \psi(s \varepsilon)=\psi\left(s^{3} \frac{\varepsilon}{s^{2}}\right) \\
& \leq \psi\left(s^{3} \lim _{k \rightarrow \infty} \sup P_{b}\left(x_{m_{k}+1}, x_{n_{k}+1}\right)\right) \\
& \quad \leq \delta \psi\left(\lim _{k \rightarrow \infty} \sup M_{s}\left(x_{m_{k}}, x_{n_{k}}\right)\right) \\
& \quad \leq \delta \psi(s \varepsilon)
\end{aligned}
$$

Since $\delta<1$, we have $\psi(s \varepsilon)=0$ and hence $\varepsilon=0$, which is a contradiction.

Therefore $\{\mathrm{xn}\}$ is a $\mathrm{Pb}$ - Cauchy sequence

Step 3: We prove that the existence of a common fixed point of $f$ and $g$.

Since $(\mathrm{X}, \mathrm{Pb})$ is a $\mathrm{Pb}$ complete and $\{\mathrm{xn}\}$ is a then from definition and lemma of [9], $\{\mathrm{xn}\}$ converges to $\mathrm{z} \in \mathrm{X}$. Therefore, we have

$$
\begin{aligned}
& \lim _{n \rightarrow \infty} P_{b}\left(x_{n}, z\right)=\lim _{n, m \rightarrow \infty} P_{b}\left(x_{n}, x_{m}\right)=0=P_{b}(z, z) \\
& \lim _{n \rightarrow \infty} x_{n}=\lim _{n \rightarrow \infty} x_{2 n+1}=\lim _{n \rightarrow \infty} x_{2 n}=z .
\end{aligned}
$$

Since $\{\mathrm{x} 2 \mathrm{n}\}$ is a sequence in $\mathrm{A}, \mathrm{A}$ is closed and $x_{2 n} \rightarrow z$, we have $\mathrm{z} \in \mathrm{A}$.

Also since $\{x 2 n+1\}$ is a sequence in $B, B$ is closed and $x_{2 n+1} \rightarrow z$, we have $\mathrm{z} \in \mathrm{B}$.

To show that $\mathrm{z}$ is a fixed point of $\mathrm{f}$ and $\mathrm{g}$. Without loss of generality, we assume that $\mathrm{f}$ is continuous.

Since $\{\mathrm{x} 2 \mathrm{n}\} \rightarrow \mathrm{z}$, we get $x_{2 n+1}=f x_{2 n} \rightarrow f_{z}$.

So, we have $\mathrm{z}=\mathrm{fz}$. Now to prove that $\mathrm{z}=\mathrm{gz}$.

Since $\mathrm{z} \in \mathrm{A}, \mathrm{z} \in \mathrm{B}$ and $\alpha(\mathrm{z}, \mathrm{z}) \geq 1$, we have

$$
\begin{gathered}
\psi\left(S^{\varepsilon} P_{b}(z, g z)\right)=\psi\left(S^{\varepsilon} P_{b}(f z, g z)\right) \\
\leq \delta \psi\left(M_{s}(z, z)\right)
\end{gathered}
$$

$$
\begin{aligned}
=\delta \psi(\max & \left.\left\{P_{b}(z, z), P_{b}(z, f z), P_{b}(z, g z), \frac{P_{b}(z, g z)+P_{b}(z, f z)}{2 s}\right\}\right) \\
& =\delta \psi\left(P_{b}(z, g z)\right) \\
& \leq \delta \psi\left(s^{3} P_{b}(z, g z)\right)
\end{aligned}
$$

Since $\delta<1$, it follows that $P_{b}(z, g z)=0$. Thus $\mathrm{z}=\mathrm{gz}$. Therefore $\mathrm{z}$ is a common fixed point of $\mathrm{f}$ and $\mathrm{g}$. This completes the proof.

The previous theorem can be proved without assuming the continuity of $f$ or $g$. For instance, We assume that $X$ satisfies following properties:

Definition 3.2

Let $(\mathrm{X}, \mathrm{Pb})$ be a partial b-metric space and $\alpha: X \times X \rightarrow[0, \infty)$ be a mapping. A space $X$ satisfies the property $\left(Q_{p_{b}}\right)$ if $\left\{x_{n}\right\}$ is a sequence in $\mathrm{X}$ such that $\alpha\left(x_{n}, x_{n+1}\right) \geq 1$ for all $n \in ¥$ and $x_{n} \rightarrow x$ as $\mathrm{n} \rightarrow \infty$, then $\alpha\left(x_{n}, x\right) \geq 1$ for all $n \in ¥$.

Theorem 3.2

Let $(\mathrm{X}, \mathrm{Pb})$ be a complete partial b-metric with coefficient $\mathrm{s} \geq 1$ and $\mathrm{A}, \mathrm{B}$ be a non-empty closed subsets of $X$.If $\alpha: X \times X \rightarrow[0, \infty), \psi:[0, \infty) \rightarrow[0, \infty)$ and $\mathrm{f}, \mathrm{g}: \mathrm{X} \rightarrow \mathrm{X}$ are four mappings such that the pair (f, $\mathrm{g}$ ) is $\alpha$ (A, B)-weakly increasing and the following condition hold:

(i) the pair (f, g) is a cyclic $\alpha$ $(\psi, A, B)_{s, \varepsilon}-$ contraction,

(ii) X satisfies the property $\left(Q_{p_{b}}\right)$,

(iii) $\alpha$ is a transitive mapping,

(iv) If $\{\mathrm{xn}\}$ is a sequence in $X$ such that $\alpha\left(x_{n}, x_{n+1}\right) \geq 1$ for all 
$n \in ¥$ and $x_{n} \rightarrow z$ as $\quad \mathrm{n} \rightarrow \infty$, then $\alpha(z, z) \geq 1$.

Then $\mathrm{f}$ and $\mathrm{g}$ have a common fixed point in $\mathrm{A} \cap \mathrm{B}$.

Proof. Now, we prove the reasoning of Theorem 3.1 step by step to construct a sequence $\{x n\}$ in $X$ with $\alpha\left(x_{n}, x_{n+1}\right) \geq 1, x_{2 n} \in A, x_{2 n+1} \in B$ for all $n \in ¥ \quad$ and $x_{n} \rightarrow z$ for some $z \in X$. Since $x_{2 n} \rightarrow z, x_{2 n+1} \rightarrow z$ and $\mathrm{A}, \mathrm{B}$ are closed in X. This implies $z \in A \cap B$.

By using the property of $\left(Q_{p_{b}}\right)$, we have $\alpha\left(x_{n}, z\right) \geq 1$ for all $n \in ¥ . \quad$ Since $\mathrm{x} 2 \mathrm{n} \in \mathrm{A}, \mathrm{z} \in \mathrm{B}$ and $\alpha\left(^{x_{n}}\right.$, z) $\geq 1$ for all $n \in ¥$, $\psi\left(S^{\varepsilon} P_{b}\left(x_{2 n+1}, g z\right)\right)=\psi\left(S^{\varepsilon} P_{b}\left(f x_{2 n}, g z\right)\right) \leq \delta \psi\left(M_{s}\left(x_{2 n}, z\right)\right)$

where

$$
\begin{gathered}
M_{s}\left(x_{n} z\right)=\max \left\{P_{b}\left(x_{2 n}, z\right), P_{b}\left(x_{2 n}, f x_{2 n}\right), P_{b}(z, g z), \frac{P_{b}\left(x_{2 n}, g z\right)+P_{b}\left(z, f x_{2 n}\right)}{2 s}\right\} \\
=\max \left\{P_{b}\left(x_{2 n}, z\right), P_{b}\left(x_{2 n}, x_{2 n+1}\right), P_{b}(z, g z), \frac{P_{b}\left(x_{2 n}, g z\right)+P_{b}\left(z, x_{2 n+1}\right)}{2}\right\}
\end{gathered}
$$

Taking the limit supremum as $\mathrm{n} \rightarrow \infty$ in the above inequality, we have

$\psi\left(S^{\varepsilon} P_{b}(z, g z)\right)=\psi\left(P_{b}(z, g z)\right)<\delta \psi\left(S^{\varepsilon} P_{b}(z, g z)\right)$

Since $\delta<1$ and $\mathrm{s} \geq 1$, we have $P_{b}(z, g z)=0$. Hence $\mathrm{z}=$ gz. Similarly, we can show that $\mathrm{fz}=\mathrm{z}$.

Thus $\mathrm{z}$ is a common fixed point of $\mathrm{f}$ and $\mathrm{g}$. This completes the proof.

\section{CONCLUSION}

In this paper we introduced and discussed about b-metric spaces and their properties.

\section{REFERENCES}

1. Shukla.S, "Partial b-metric spaces and fixed point theorems", Mediterr. J. Math. vol.11 (2014), 703-711.

2. Bakhtin I.A, "The contraction mapping principle in quasi metric spaces". Funct. Anal. Unianowsk Gos. Ped. Inst. Vol. 30, 26-37 (1989).

3. Czerwik. S, "Contraction mappings in b-metric spaces", Acta Mathematica et Informatica Universitatis Ostraviensis Vol. 5-11 (1993).

4. Mathews. S.G, "Partial metric topology", in Proc. 8th Summer conference on General Topology and Application. Ann. New York Acad. Sci. Vol. 728, 183-197 (1994).

5. Kirk. W.A, Srinivasan. P.S, Veeramani. P, "Fixed points for mappings satisfying cyclical contractive conditions", Fixed Point Theory Vol. 4, 79-89 (2003).

6. Sintunavarat. W, " Generalized Ulam-Hyers stability, well-posedness and limit shadowing of fixed point problems for * - · -contraction mapping in metric spaces” , Sci. World J. 2014, 569174 (2014).

7. Latif. A, Mongkolkeha. C, Sintunavarat. W, " Fixed point theorems for generalized - - - -weakly contraction mappings in metric spaces and applications" , Sci. World J. 2014, 784207 (2014).

8. Khan. M.S, Swaleh. M, Sessa. S, "Fixed point theorems by altering distances between the points", Bull. Aust. Math. Soc. Vol. 30, 1-9(1984)

9. Nguyen Van Dung and Vo Thi Le Hang "Remarks on partial b-metric spaces and fixed point theorems", Aug. 1987, pp. 740-741 [Dig. $9^{\text {th }}$ Annu. Conf. Magnetics Japan, 1982, p. 301].

\section{AUTHORS PROFILE}

A. Jennie Sebasty Pritha Department of Mathematics,Holy Cross College (Autonomous), Trichy-620 002. email: jennipretha@gmail.com.

Dr.U.Karuppiah Department of Mathematics, St. Joseph's College(Autonomous), Trichy-620 002. email: u.karuppiah@gmail.com. 